\title{
Life-threatening bronchiolitis related to electronic cigarette use in a Canadian youth
}

\author{
Simon T. Landman MBBS, Inderdeep Dhaliwal MSc(HQ) MD, Constance A. Mackenzie MD MSc, Tereza \\ Martinu MD MHS, Andrew Steel MBBS, Karen J. Bosma MD
}

- Cite as: CMAJ 2019 December 2;191:E1321-31. doi: 10.1503/cmaj.191402; early-released November 21, 2019

See related article at www.cmaj.ca/lookup/doi/10.1503/cmaj.191503

\begin{abstract}
BACKGROUND: Although electronic cigarettes (e-cigarettes) were initially marketed as a potential smoking-cessation aid and a safer alternative to smoking, the long-term health effect of e-cigarette use ("vaping") is unknown. Vaping e-liquids expose the user to several potentially harmful chemicals, including diacetyl, a flavouring compound known to cause bronchiolitis obliterans with inhalational exposure ("popcorn worker's lung").
\end{abstract}

CASE DESCRIPTION: We report the case of a 17-year-old male who presented with intractable cough, progressive dyspnea and malaise after vaping flavoured e-liquids and tetrahydrocannabinol intensively. Initial physical examination showed fever, tachycardia, hypoxemia, and bibasilar inspiratory crackles on lung auscultation.
Computed tomography of the chest showed diffuse centrilobular "tree-inbud" nodularity, consistent with acute bronchiolitis. Multiple cultures, including from 2 bronchoalveolar lavage samples, and biopsy stains, were negative for infection. He required intubation, invasive mechanical ventilation and venovenous extracorporeal membrane oxygenation (ECMO) for refractory hypercapnia. The patient's condition improved with high-dose corticosteroids. He was weaned off ECMO and mechanical ventilation, and discharged home after 47 days in hospital. Several months after hospital discharge, his exercise tolerance remained limited and pulmonary function tests showed persistent, fixed airflow obstruction with gas trapping. The patient's clinical picture was suggestive of possible bronchiolitis oblit- erans, thought to be secondary to inhalation of flavouring agents in the e-liquids, although the exact mechanism of injury and causative agent are unknown.

INTERPRETATION: This case of severe acute bronchiolitis, causing near-fatal hypercapnic respiratory failure and chronic airflow obstruction in a previously healthy Canadian youth, may represent vaping-associated bronchiolitis obliterans. This novel pattern of pulmonary disease associated with vaping appears distinct from the type of alveolar injury predominantly reported in the recent outbreak of cases of vapingassociated pulmonary illness in the United States, underscoring the need for further research into all potentially toxic components of e-liquids and tighter regulation of e-cigarettes.
E lectronic cigarettes (e-cigarettes) are the most commonly used nicotine products among Canadian youth; a 2017 study estimated that 272000 Canadians aged 15 to 24 years had used e-cigarettes in the last 30 days. ${ }^{1}$ First available in China in 2004 and in the United States in 2006, ${ }^{2}$ e-cigarettes are battery-powered devices that aerosolize various substances for inhalation, including nicotine, tetrahydrocannabinol (THC), cannabidiol and flavouring agents that may contain diacetyl, a compound known to cause pulmonary toxicity. ${ }^{3}$ Since its introduction to the North American market, use of e-cigarettes, or "vaping," has continued to rise. ${ }^{4}$
Although use of this heavily marketed device is rapidly growing and becoming commonplace in Canada - particularly among youth - the impact of e-cigarettes on health is poorly understood. In recent years, several patterns of adverse reactions to vaping have been reported, including hypersensitivity pneumonitis, ${ }^{5-8}$ diffuse alveolar hemorrhage,${ }^{9}$ organizing pneumonia, ${ }^{10-14}$ acute eosinophilic pneumonia ${ }^{15,16}$ and lipoid pneumonia. ${ }^{17-21}$ Most recently, a cluster of 53 cases in the US was described as having hypoxemia and bilateral ground-glass opacities, consistent with a diffuse alveolar damage pattern of lung injury. ${ }^{22}$ As of Nov. 13, 2019, 2172 cases of "e-cigarette, or 
vaping, product use-associated lung injury" (EVALI) have been reported to the Centers for Disease Control and Prevention (CDC) in the US, with 42 confirmed deaths. ${ }^{23}$ The specific compound(s) or ingredient(s) causing lung injury is still under investigation, but vitamin $\mathrm{E}$ acetate has been identified in the bronchoalveolar lavage fluid samples from 29 patients with EVALI. ${ }^{23}$ Although inhalation of diacetyl is known to cause flavouring-related lung disease in factory workers (bronchiolitis obliterans, or "popcorn worker's lung"), to date, there have been no reported cases in the medical literature of bronchiolitis obliterans from vaping.

We present a case of severe acute bronchiolitis associated with vaping, causing near-fatal hypercapnic respiratory failure requiring intubation and extracorporeal membrane oxygenation (ECMO) in a 17-year-old male. Several months after resolution of the acute critical illness, this previously healthy youth displayed persistent, fixed airflow obstruction, which may represent bronchiolitis obliterans. This novel disease pattern of airway injury associated with vaping leading to chronic obstruction appears to be distinct from the alveolar injury characterizing the EVALI cases recently reported in the US, and the 7 confirmed or probable cases in Canada, ${ }^{24,25}$ highlighting the need for further research and regulation of e-cigarettes.

\section{Methods}

\section{Case description}

All 6 coauthors were involved in the clinical care of this patient. The information included in this report was garnered from direct communication, medical records and review of imaging and pathology.

\section{Literature review}

With the help of a medical librarian, we conducted a comprehensive literature search of the MEDLINE and Embase electronic databases, using the OvidSP search interface, from inception to Oct. 30, 2019. No language restrictions were applied. A sensitive search strategy was used to identify relevant case reports and case series using a combination of subject headings, phrases and keywords (Appendices 1 and 2, available at www.cmaj.ca/lookup/suppl/doi:10.1503/ cmaj.191402/-/DC1). The reference lists of identified case reports and an Internet search for other related literature also contributed to gathering evidence. We included all case reports (abstracts, conference presentations, full manuscripts) of any type of respiratory illness in humans related to vaping; we excluded nonrespiratory illness, animal studies and mechanical injuries from device malfunction. One author (S.T.L.) reviewed abstracts and full texts to select relevant articles and extracted data, and 2 authors (K.J.B. and I.D.) reviewed and verified data presented in Table 1.

\section{Ethics approval}

The patient and his parents provided written informed consent for publishing this case report.

\section{Results}

\section{Case description}

A previously healthy 17-year-old male presented with a 1-week history of productive cough, dyspnea and fever. He was born in Canada, worked at a fast-food restaurant, and said that he did not use alcohol or smoke cigarettes; there was no recent travel. He had vaped daily for the last 5 months. He alternated between different flavour cartridges, specifically, "dew mountain," "green apple" and "cotton candy" flavours bought through an online Canadian retailer. He regularly added THC to his vaping fluid and occasionally inhaled marijuana via a bong. Samples from the cartridges vaped had been discarded and were not available for further examination; however, collateral history from the patient's family suggested he was vaping heavily before his presentation and used very deep inhalations when vaping or using his bong.

The patient developed a severe, intractable cough that caused him to seek medical attention. He was seen in the emergency department of his local community hospital 1 week after his symptoms began, was diagnosed with pneumonia, and was discharged with a prescription for azithromycin.

Five days later, he re-presented at the community hospital emergency department with worsening dyspnea, malaise and nausea. He was found to be febrile, tachycardic and hypoxemic, requiring supplemental oxygen via nasal cannula. He had bibasilar inspiratory crackles on lung auscultation on physical examination. Blood tests showed neutrophil-predominant leukocytosis (leukocytes 19.4 [normal 4.0-10.0] $\times 10^{9} / \mathrm{L}$, neutrophils 17.4 [normal $2.0-7.5$ ] $\times 10^{\circ} / \mathrm{L}$ ), and normal lactate and electrolyte levels.

The patient was admitted to the community hospital and given ceftriaxone and azithromycin, administered intravenously. Radiography of the chest showed diffuse micronodular opacities bilaterally (Figure 1), and computed tomography showed diffuse centrilobular "tree-in-bud" nodularity with subpleural sparing consistent with bronchiolitis (Figure 2). The patient required intubation on the fifth day of hospital admission because of increased work of breathing and tachypnea at 50 breaths/min. His arterial blood gas values before intubation were $\mathrm{pH} 7.34, \mathrm{PCO}_{2} 47 \mathrm{~mm} \mathrm{Hg}$ and $\mathrm{PO}_{2} 78 \mathrm{~mm} \mathrm{Hg}$.

One day after intubation, the patient underwent bronchoscopy that showed bilateral frothy, mucopurulent secretions but no organisms on staining or culture of bronchoalveolar lavage. Antibiotics were broadened to piperacillin-tazobactam and amphotericin $\mathrm{B}$, and he was transferred to a tertiary care intensive care unit (ICU) on day 8 of hospital admission.

On arrival to the tertiary care ICU, the patient's $\mathrm{PaO}_{2}$ was $289 \mathrm{~mm} \mathrm{Hg}$ on $\mathrm{FiO}_{2} 1.0\left(\mathrm{PaO}_{2} / \mathrm{FiO}_{2} 289\right), \mathrm{PCO}_{2}$ was $109 \mathrm{~mm} \mathrm{Hg}$ and $\mathrm{pH}$ was 7.12. A repeat bronchoscopy was done and again showed mucopurulent secretions bilaterally. Repeat microbiological investigations were negative, including repeat bronchoalveolar lavage bacterial and fungal cultures, acid-fast bacilli, galactomannan, Legionella, respiratory viral panel, and Pneumocystis jiroveci and blood cultures. Investigations for $\mathrm{Q}$ fever, viral hepatitis, HIV serology, and vasculitis, including antinuclear antibodies, 
Table 1: Patterns of disease shown in case reports of vaping-associated pulmonary illnesses: an overview of the medical literature up to Oct. 30, 2019*

\begin{tabular}{|c|c|c|c|c|}
\hline $\begin{array}{l}\text { Type of lung injury or } \\
\text { predominant disease pattern }\end{array}$ & $\begin{array}{l}\text { No. of } \\
\text { cases }\end{array}$ & Age and sex & Associated imaging findings & Level of care required \\
\hline Organizing pneumonia ${ }^{10-13,26}$ & 12 & $\begin{array}{l}64 \mathrm{M}, 40 \mathrm{~F}, 54 \mathrm{M} \\
22 \mathrm{M}, 20 \mathrm{M}, 21 \mathrm{M} \\
28 \mathrm{M}, 19 \mathrm{M}, 28 \mathrm{M} \\
38 \mathrm{M}, 35 \mathrm{M}, 39 \mathrm{M}\end{array}$ & $\begin{array}{l}1 \text { patchy infiltrates, } 11 \text { diffuse GGO, } \\
1 \text { tree in bud, } 1 \text { pneumothorax with bilateral } \\
\text { central opacities, bilateral reticulonodular } \\
\text { opacities with subpleural sparing }\end{array}$ & $\begin{array}{l}7 \text { hospital ward, } 2 \text { ICU, } \\
3 \text { unknown }\end{array}$ \\
\hline $\begin{array}{l}\text { Acute fibrinous pneumonitis with } \\
\text { organization }^{26}\end{array}$ & $11 \ddagger$ & $\begin{array}{l}44 \mathrm{M}, 42 \mathrm{M}, 51 \mathrm{M} \\
25 \mathrm{M}, 21 \mathrm{M}, 34 \mathrm{~F} \\
28 \mathrm{M}, 54 \mathrm{~F}, 67 \mathrm{M} \\
19 \mathrm{M}, 40 \mathrm{M}\end{array}$ & $\begin{array}{l}5 \text { diffuse GGO, } 2 \text { bilateral centrilobular GGO, } \\
1 \text { perihilar GGO, } 1 \text { tree in bud, } 1 \text { diffuse } \\
\text { bronchocentric micronodular GGO, } 1 \text { diffuse } \\
\text { bilateral opacities }\end{array}$ & 11 unknown \\
\hline Lipoid pneumonia $^{17-21}$ & 10 & $\begin{array}{l}42 F, \text { “young” F, 35F, } \\
31 F, 20 \S, 23 \S, 23 \S \text {, } \\
25 \S, 29 \S, 47 \S\end{array}$ & $\begin{array}{l}8 \text { diffuse GGO, } 3 \text { “crazy paving," } \\
1 \text { consolidation, } 1 \text { basilar GGO }\end{array}$ & 6 hospital ward, 4 ICU \\
\hline $\begin{array}{l}\text { Acute alveolitis or diffuse alveolar } \\
\text { damage }{ }^{9,13,26-28}\end{array}$ & 89 & $\begin{array}{l}46 \mathrm{M}, 33 \mathrm{M}, 35 \mathrm{M} \\
61 \mathrm{M}, 47 \mathrm{~F}, 21 \mathrm{M}, 34 \mathrm{~F} \\
28 \mathrm{M}\end{array}$ & $\begin{array}{l}6 \text { bilateral diffuse GGO, } 1 \text { traction } \\
\text { bronchiectasis }\end{array}$ & $\begin{array}{l}1 \text { hospital ward, } 6 \text { ICU, } \\
1 \text { unknown }\end{array}$ \\
\hline $\begin{array}{l}\text { Pneumomediastinum or } \\
\text { pneumothorax } x^{29-33}\end{array}$ & 6 & $\begin{array}{l}17 \mathrm{M}, 16 \mathrm{M}, 21 \mathrm{M} \\
15 \mathrm{M}, 16 \mathrm{M}, 18 \mathrm{M}\end{array}$ & $\begin{array}{l}2 \text { pneumomediastinum, } 1 \text { tension } \\
\text { pneumothorax, } 3 \text { nontension pneumothorax }\end{array}$ & 6 hospital ward \\
\hline Hypersensitivity pneumonitis ${ }^{5-8}$ & 4 & $73 F, 16 F, 23 M, 18 F$ & $\begin{array}{l}2 \text { diffuse GGO, } 2 \text { septal thickening, } 1 \text { traction } \\
\text { bronchiectasis, } 1 \text { honeycombing, } 1 \text { diffuse } \\
\text { nodules }\end{array}$ & $\begin{array}{l}2 \text { hospital ward, } 1 \text { ICU } \\
\text { with ECMO, } 1 \text { ICU } \\
\text { without ECMO }\end{array}$ \\
\hline Granulomatous disease ${ }^{34,35}$ & 2 & $43 \mathrm{~F}, 34 \mathrm{~F}$ & 2 bilateral nodules & 2 hospital ward \\
\hline Eosinophilic pneumonia ${ }^{15,16}$ & 2 & $18 \mathrm{~F}, 20 \mathrm{M}$ & $\begin{array}{l}2 \text { diffuse GGO, } 1 \text { airspace disease, } 1 \text { coalescing } \\
\text { nodules }\end{array}$ & $1 \mathrm{ICU}, 1$ hospital ward \\
\hline Status asthmaticus ${ }^{36}$ & 2 & $16 \mathrm{M}, 14 \mathrm{~F}$ & 2 pneumomediastinum & $2 \mathrm{ICU}$ with ECMO \\
\hline Bronchitis $^{37,38}$ & 2 & $43 \mathrm{M}, 56 \mathrm{~F}$ & $\begin{array}{l}1 \text { no acute abnormality, } 1 \text { diffuse GGO, } 1 \text { "crazy } \\
\text { paving" }\end{array}$ & $\begin{array}{l}1 \text { outpatient, } 1 \text { hospital } \\
\text { ward }\end{array}$ \\
\hline Inhalational injury ${ }^{39,40}$ & 2 & $35 \mathrm{~F}, 60 \mathrm{M}$ & $\begin{array}{l}1 \text { nodular infiltrates, } 1 \text { mediastinal } \\
\text { adenopathy, } 1 \text { bilateral GGO }\end{array}$ & $\begin{array}{l}1 \text { ICU with ECMO, } \\
1 \text { hospital ward }\end{array}$ \\
\hline $\begin{array}{l}\text { Respiratory bronchiolitis- } \\
\text { associated interstitial lung } \\
\text { disease }^{41}\end{array}$ & 1 & $33 \mathrm{M}$ & Tree in bud & Hospital ward \\
\hline Diffuse alveolar hemorrhage ${ }^{9}$ & 1 & $33 \mathrm{M}$ & Diffuse GGO & $\mathrm{ICU}$ \\
\hline $\begin{array}{l}\text { Hypereosinophilia with } \\
\text { eosinophilic asthma }{ }^{42}\end{array}$ & 1 & $18 \mathrm{~F}$ & NA & Outpatient \\
\hline $\begin{array}{l}\text { Transient nodules in lung and } \\
\text { liver }^{43}\end{array}$ & 1 & $45 \mathrm{~F}$ & Multiple pulmonary and hepatic nodules & Hospital ward \\
\hline Pleural effusion ${ }^{44}$ & 1 & $63 \mathrm{M}$ & Left-sided pleural effusion & Hospital ward \\
\hline $\begin{array}{l}\text { Severe persistent airflow } \\
\text { obstruction in a long-standing } \\
\text { smokert }^{45}\end{array}$ & 1 & $45 \mathrm{M}$ & Patchy GGO, mosaic attenuation & Outpatient \\
\hline Upper airway damage ${ }^{46}$ & 1 & $30 \mathrm{M}$ & $\begin{array}{l}\text { Moderate uvulitis and edema of the } \\
\text { paratracheal musculature }\end{array}$ & $\mathrm{ICU}$ \\
\hline \multicolumn{5}{|c|}{$\begin{array}{l}\text { Note: } \mathrm{ECMO}=\text { extracorporeal membrane oxygenation, } \mathrm{F}=\text { female, } \mathrm{GGO}=\text { ground-glass opacities, } \mathrm{ICU}=\text { intensive care unit, } \mathrm{M}=\text { male, } \mathrm{NA}=\text { not available. } \\
\text { * "Case reports" refers to individual cases reported with pathology and imaging findings. Table } 1 \text { does not include the } 53 \text {-person case cohort published by Layden et al. }{ }^{22} \text { or } 805 \text { cases } \\
\text { reported by Perrine et al.47 } \\
\text { †Patient was a long-standing smoker. No baseline pulmonary function tests before illness. } \\
\text { fOne death. } \\
\text { \$Sex not defined }\end{array}$} \\
\hline
\end{tabular}

extractable nuclear antigen and antineutrophil cytoplasmic antibody, were also negative. The cell differential from bronchoalveolar lavage was $83 \%$ neutrophils. Transbronchial biopsies sampling 75-100 alveoli showed nonspecific acute inflammation and reactive changes, although there were no airway fragments present for comment (Figure 3). Staining for lipoid pneumonia was not completed. Iatrogenic pneumothorax developed in the patient, and he required a right-sided surgical chest tube. 


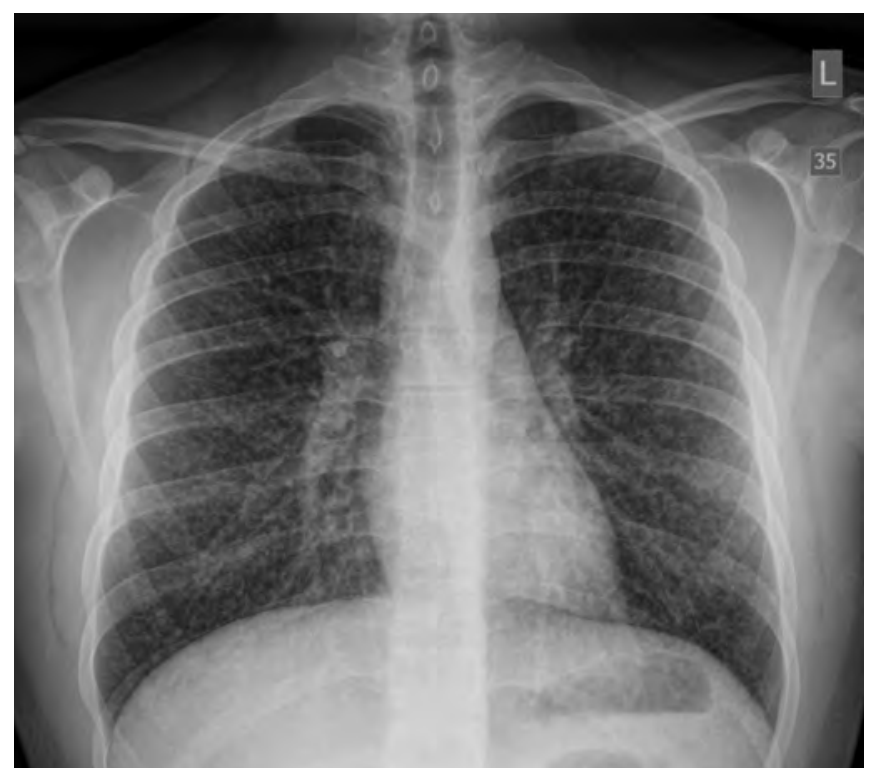

Figure 1: Portable frontal chest radiograph in a 17-year-old male taken on day 2 of a community hospital admission showing diffuse micronodular opacities in both lungs.
On his ninth day of hospital admission, the patient required initiation of venovenous ECMO for severe refractory hypercapnia (maximum $\mathrm{PCO}_{2}>130 \mathrm{~mm} \mathrm{Hg}$ ), decreased lung compliance and difficulty ventilating. Methylprednisolone $100 \mathrm{mg}$ daily administered intravenously was started. The patient's condition stabilized on ECMO with normal blood gases. Trials of pressure-support ventilation were poorly tolerated as any reduction in sedation led to severe coughing spells. Similarly, ECMO support could be successfully reduced while the patient was under deep sedation, but ECMO weaning was not possible with lightening sedation, because of intractable coughing. A tracheostomy was inserted on day 16 of hospital admission (11 d after intubation) in case the endotracheal tube was stimulating the patient's cough. His cough persisted after the tracheostomy and was resistant to nebulized and intravenous opioids, enteral codeine and gabapentin.

Given that the CT showed bronchiolitis, with a negative infectious workup, and that the patient had inhalational exposure to flavouring agents with a lack of response to moderate-dose corticosteroids, we were concerned that the process developing in his lungs could be bronchiolitis obliterans and therefore consulted
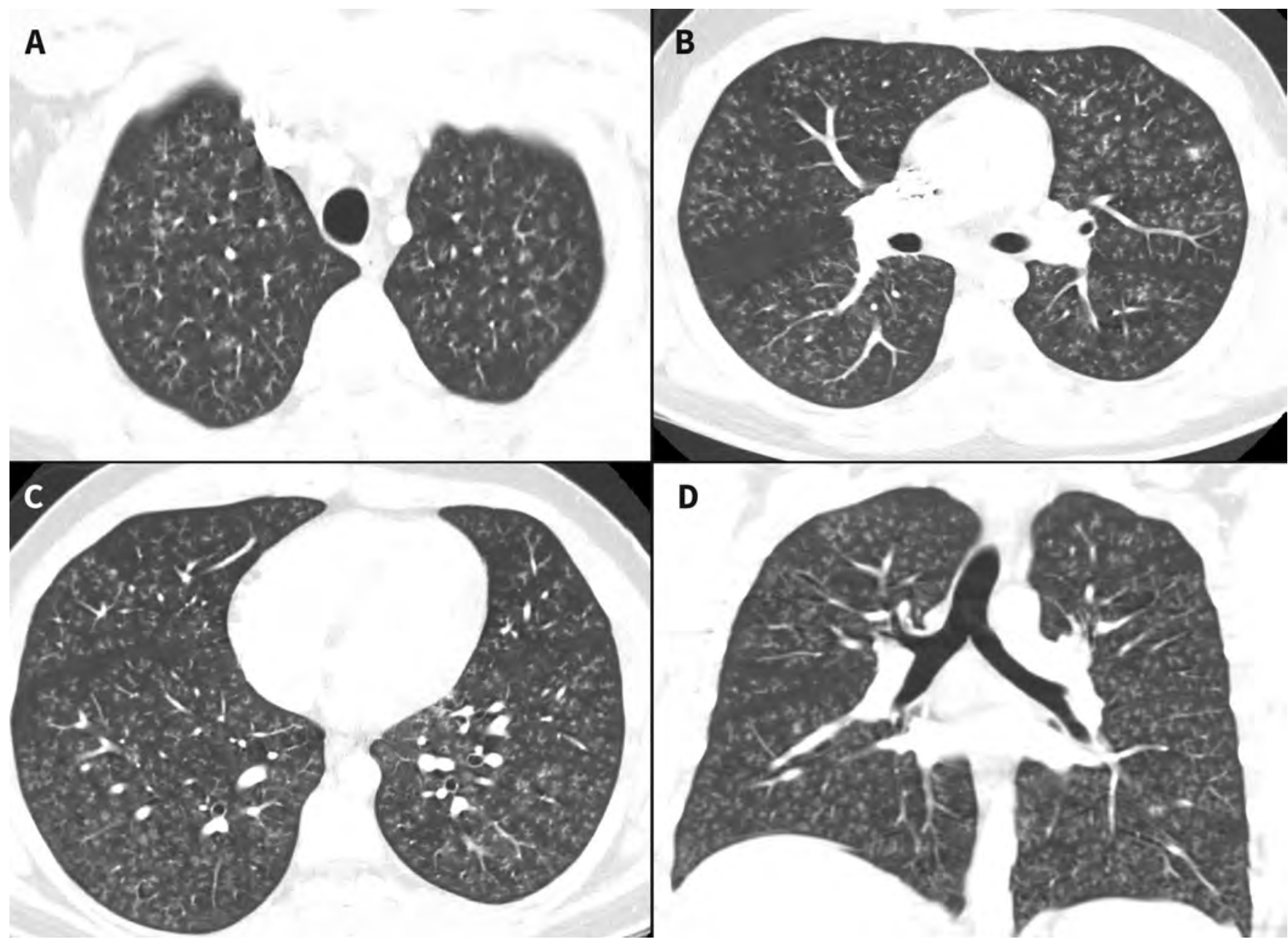

Figure 2: Computed tomography chest imaging on day 1 of hospital admission. Axial (panels A, B and C) and coronal (panel D) images show diffuse bronchiolitis manifested by innumerable tree-in-bud opacities throughout both lungs with subpleural sparing. Note the absence of mosaic attenuation, ground-glass opacity and consolidation. 
the regional lung transplant team. A surgical lung biopsy to confirm the diagnosis was considered but deemed too risky. The patient was transferred on ECMO to the lung transplant centre on day 21 of hospital admission for further evaluation.

Following transfer, the patient received intravenous methylprednisolone $1 \mathrm{~g} / \mathrm{d}$ for 3 days, followed by a taper, with slow improvement over the following 2 weeks. He was weaned from ECMO and the ventilator, had his tracheostomy tube removed and was discharged home on a tapering dose of steroids after a total of 47 days in hospital.

The patient's pulmonary physiology at 1-month follow-up showed severe obstruction with gas trapping, with a forced expiratory volume in 1 second $\left(\mathrm{FEV}_{1}\right)$ of $1.28 \mathrm{~L}$ ( $31 \%$ predicted), forced vital capacity (FVC) of $2.56 \mathrm{~L}$ ( $52 \%$ predicted), $\mathrm{FEV}_{1} / \mathrm{FVC}$ of $50 \%$, residual volume of $3.55 \mathrm{~L}$ (227\% predicted), normal total lung capacity (6.02 L, 91\% predicted) and low-normal diffusion capacity corrected for alveolar volume ( $99 \%$ predicted) (Figure 4). He was started on mometasone-formoterol 200/5 $\mu \mathrm{g}$ metered dose inhaler (MDI) 2 inhalations twice daily via spacer and tiotropium $2.5 \mathrm{mg}$ mist inhaler 2 inhalations once daily, with salbutamol $100 \mu \mathrm{g}$ MDI 2 puffs as needed for dyspnea.
The patient's physiology improved slightly at 2 months after discharge, with a $\mathrm{FEV}_{1}$ of $44 \%$ predicted. Repeat chest CT showed improvement but not full resolution of the centrilobular nodules and new mild bronchial dilation within multiple basilar segments of both lower lobes, favoured to represent early developing bronchiectasis. He was instructed to restart prednisone at a dose of $0.5 \mathrm{mg} / \mathrm{kg}$. At 3 months after discharge, his $\mathrm{FEV}_{1}$ was $55 \%$ predicted in keeping with persistent moderate airflow obstruction. He was clinically improving, albeit with limited activity tolerance. His prednisone dose was weaned to $15 \mathrm{mg}$ daily. At 4 months, his $\mathrm{FEV}_{1}$ was slightly lower at $45 \%$ predicted, with no improvement postbronchodilator. He remained abstinent of e-cigarettes, marijuana and tobacco products.

This case was reported (S.T.L. and C.A.M.) to the Government of Canada through the consumer product incident report system on Aug. 20, 2019, under the Canada Consumer Product Safety Act. ${ }^{48}$ Additional case information was provided to the Tobacco and Vaping Compliance and Enforcement Program on Aug. 30, 2019, and follow-up communication was initiated by the authors (I.D. and S.T.L.) to Health Canada on Sept. 3, 2019.49 This case remains under investigation. ${ }^{50}$

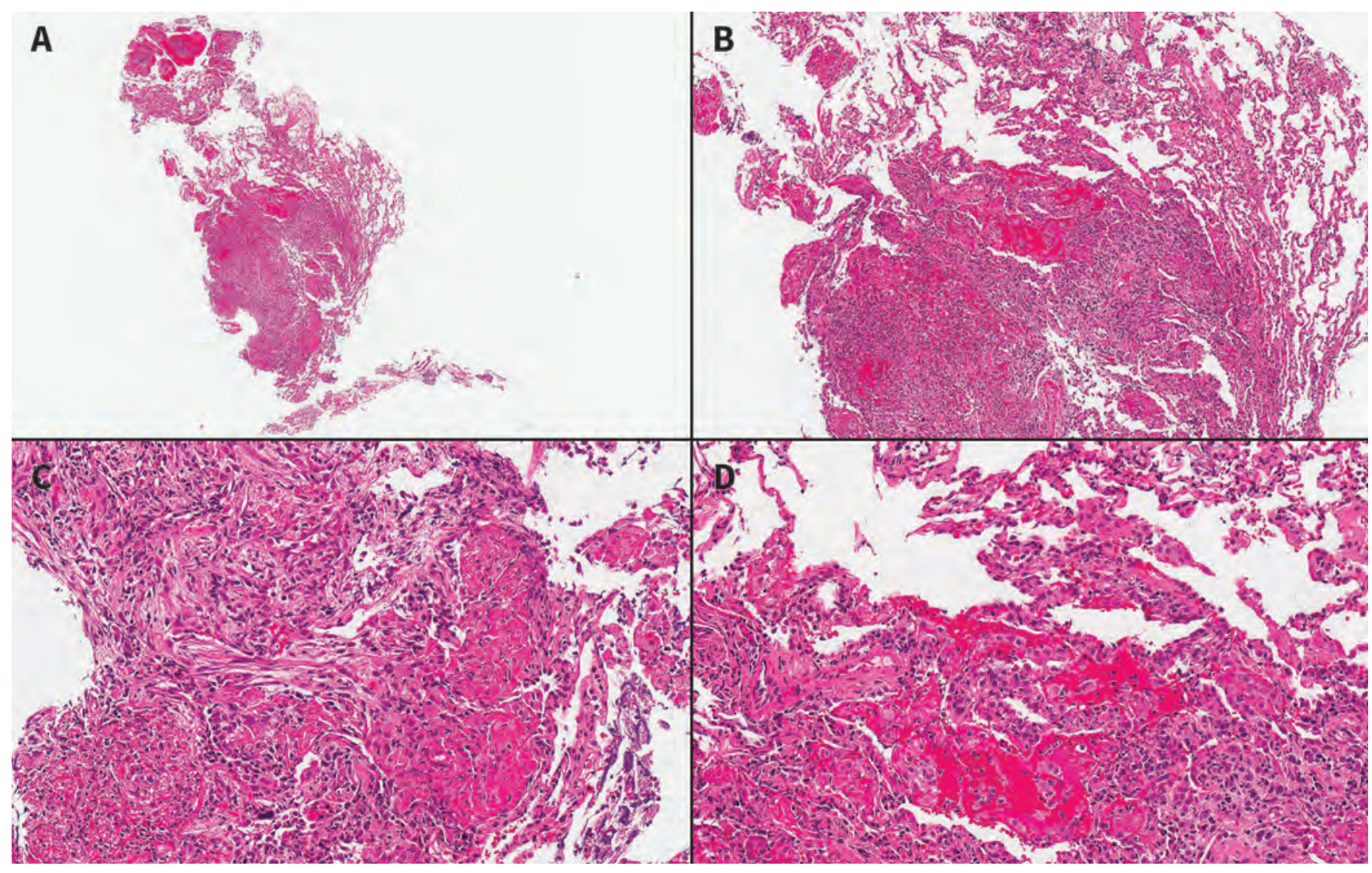

Figure 3: Histological sections of a transbronchial biopsy of the right lower lobe on day 8 of hospital admission at low (panel A, original magnification $\times 2$ ), medium (panel B, original magnification $\times 4$ ), high (panel C, original magnification $x 10$ ) and highest magnification (panel D, original magnification $\times 20$ ) (hematoxylin and eosin stain). There is mild interstitial septal thickening secondary to acute inflammatory cells in the septi and type 2 pneumocyte hyperplasia (panel C). The airspaces are distended by a mixture of fibrin balls, neutrophils, macrophages and myofibroblast proliferation, with incorporation of myofibroblasts into the septi (panel D). These findings represent nonspecific acute inflammation and reactive changes in the airspaces. No bronchial mucosa is present for evaluation. The etiology of the findings is not identified. No infectious organisms are identified. Vasculitis and granulomatous inflammation is not identified. Hyaline membranes are not identified. Note the absence of viral cytopathic changes and paucity of foamy macrophages. 

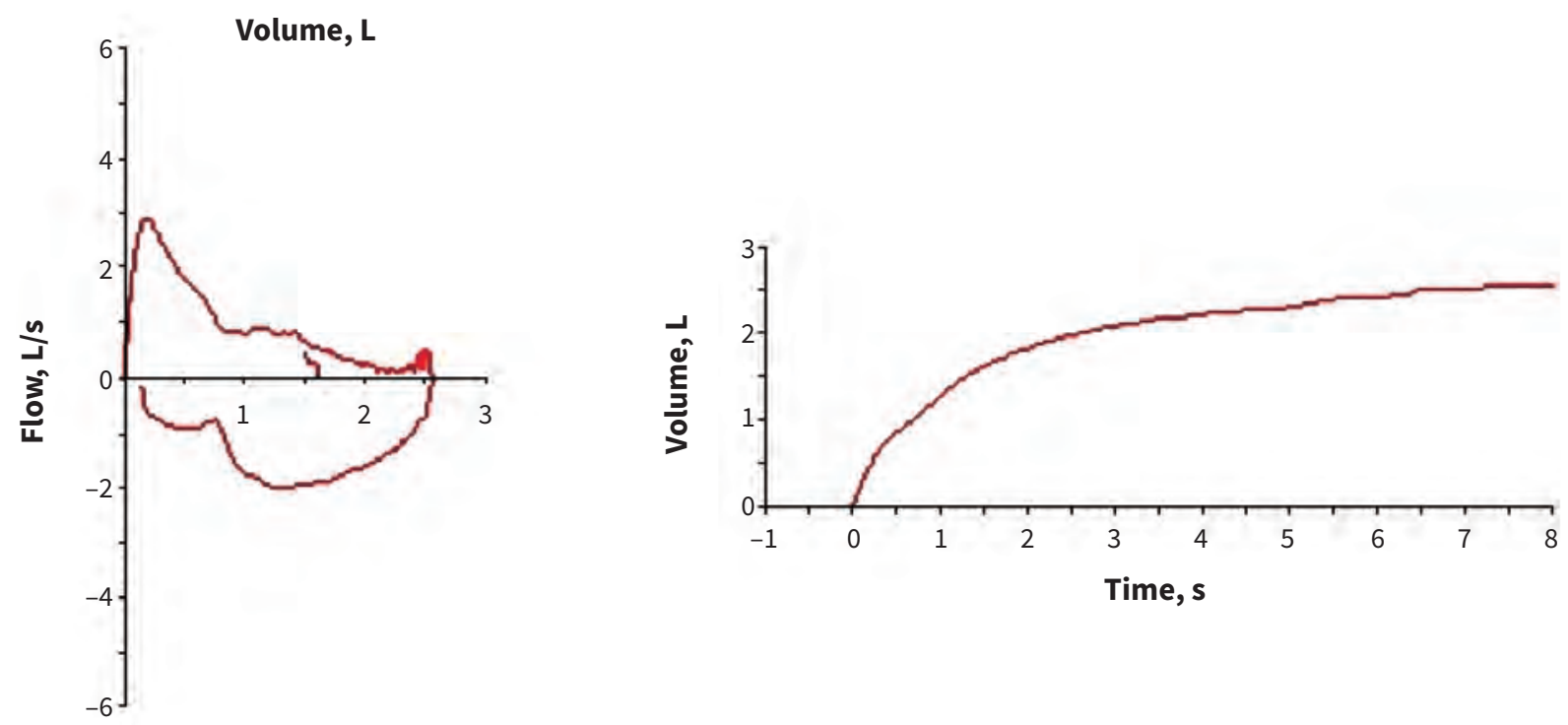

Figure 4: Flow-volume loop at 1-month follow-up showing severe airflow obstruction.

\section{Literature review}

Our search strategy identified 1442 records, of which 118 were case reports. After removal of duplicates, 83 records were reviewed; 37 did not meet our eligibility criteria, leaving 46 studies to be included in our qualitative synthesis (Figure 5). Published case reports of vaping-associated pulmonary disease date back to 2012, with an increase in reported cases over the last 3 years (Figure 6). From 2012 to Aug. 30, 2019 (before publication of the CDC investigation), there were 30 publications ${ }^{5-12,15-20,27,29-31,34,36-46}$ identifying a diverse array of vapingassociated pulmonary insults, with varying imaging and pathological findings, but no reported deaths (Table 1). From Sept. 1 to Oct. 30, 2019, an additional 13 publications ${ }^{13,21,22,26,28,32,33,35,47,51-54}$ were identified through our search strategy (Table 1).

\section{Interpretation}

This case of life-threatening acute bronchiolitis posed a diagnostic and therapeutic challenge. Given the patient's intense vaping exposure to flavoured e-liquid and negative workup for other causes of bronchiolitis, we suspected that bronchiolitis obliterans might have been developing in this patient as in microwave-popcorn factory workers exposed to occupational inhalation of diacetyl. ${ }^{55-57}$ We referred him to a lung transplant centre for further evaluation and reported the case to authorities (Government of Canada's consumer product incident report system) as an adverse reaction to a consumer product, e-cigarettes. Subsequently, media reports brought to light an outbreak of cases of hypoxemic pulmonary illness related to vaping, with a large proportion reporting use of THC. Concerned that this case might be similar, we reported it to Health Canada for further investigation. This index case highlights the need for clinicians and the public to be aware of the varying presentations of vaping-related illness and the potential acute and chronic effects of vaping, as well as the need for further research into the safety and toxicity of e-liquid compounds, and tighter regulation of e-cigarettes in Canada.

This patient had severe, acute bronchiolitis, possibly related to inhalational injury from vaping, with several features suggestive of subsequent early bronchiolitis obliterans. On arrival in our tertiary care ICU, this intubated patient had severe airflow obstruction with refractory hypercapnia requiring rescue therapy with ECMO, and a CT scan showing a treein-bud pattern. "Tree in bud" describes small centrilobular, well-defined nodules of soft-tissue attenuation connected to linear branching opacities. These nodules can represent bronchiolar inflammation and peribronchial fibrosis, and suggest small airways pathology. ${ }^{58}$ Diffuse tree-in-bud nodularity is most commonly associated with bacterial or viral infections, but can also be found with aspiration, posttransplant and inhalational exposure to toxins. ${ }^{59}$

For our patient, other infectious or inflammatory etiologies for the tree-in-bud opacities we observed were ruled out. Even though bronchoalveolar lavage and transbronchial biopsies were obtained after initiation of antibiotics, stains of alveolar tissue would have shown evidence of viral, bacterial or fungal elements had they been present, whether such organisms grew in culture or not. Furthermore, his condition improved with high-dose intravenous steroids but not with wide-spectrum antimicrobials, making an infectious etiology less likely. Transbronchial biopsies ruled out diffuse alveolar damage, organizing pneumonia and hypersensitivity pneumonitis as potential etiologies for the centrilobular tree-in-bud pattern. This led us to consider toxic inhalational exposure from vaping as the cause of the acute bronchiolitis and, given the exposure to flavouring compounds in the e-liquids, we postulated that bronchiolitis obliterans could be developing in this patient. 


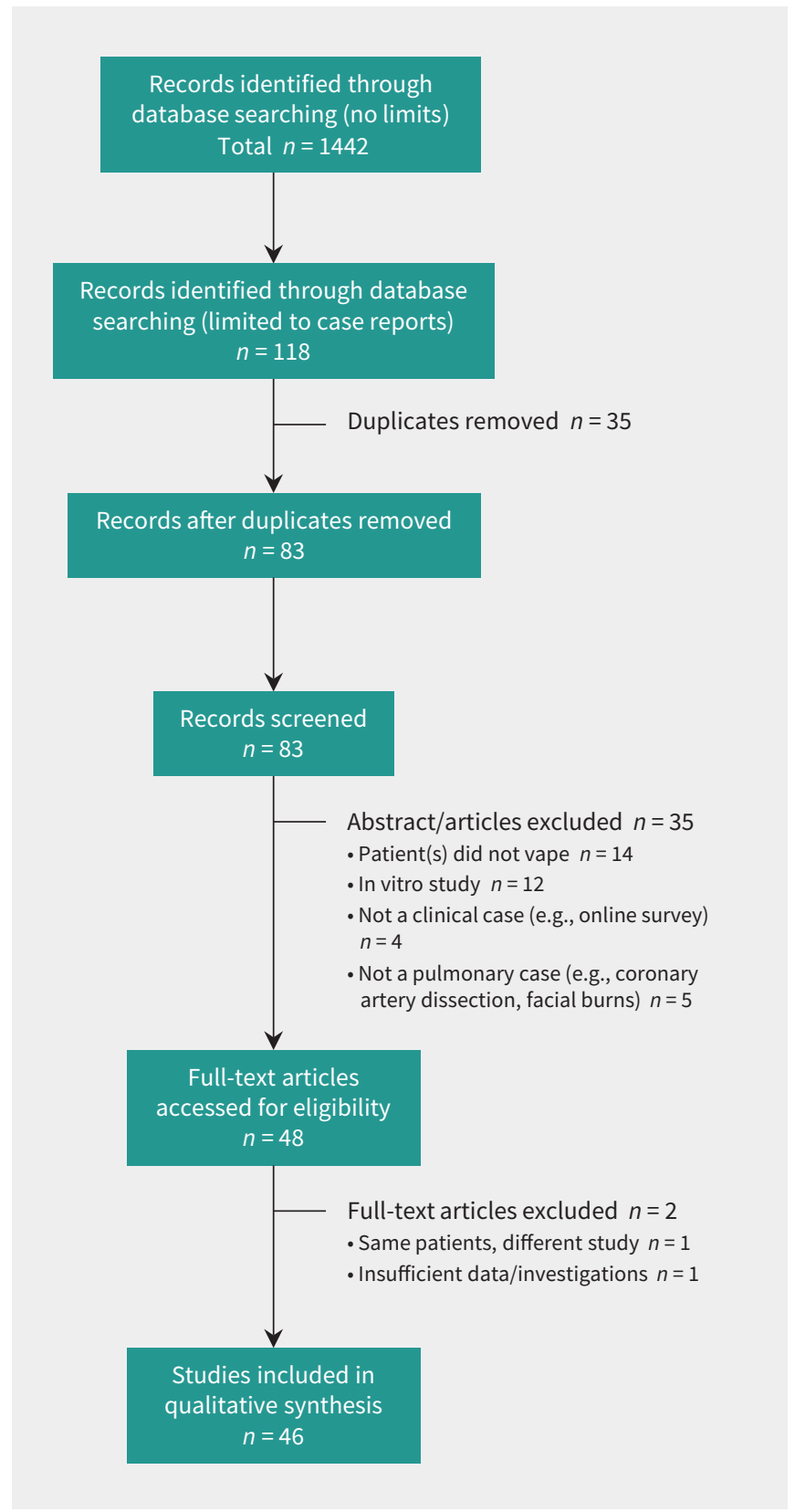

Figure 5: Flow diagram showing selection of relevant published case studies.

Bronchiolitis obliterans refers to "the clinical syndrome associated with small airways injury caused by a spectrum of inhalational, infectious, and drug exposures, and also lung or hematopoietic cell transplantation." dyspnea, airflow limitation that is not reversible by inhaled bronchodilator, and a chest radiograph that shows normal or hyperinflated lungs." ${ }^{60}$ Flavouring-associated lung disease is a form of bronchiolitis obliterans recognized as a rare but serious complication in workers exposed to flavouring chemicals such as diacetyl while working in the food and flavouring industry, including manufacturing of microwave popcorn, flavourings and diacetyl, as well as coffee-processing facilities. ${ }^{61}$ Lung-function abnormalities in these cases typically show irreversible airflow

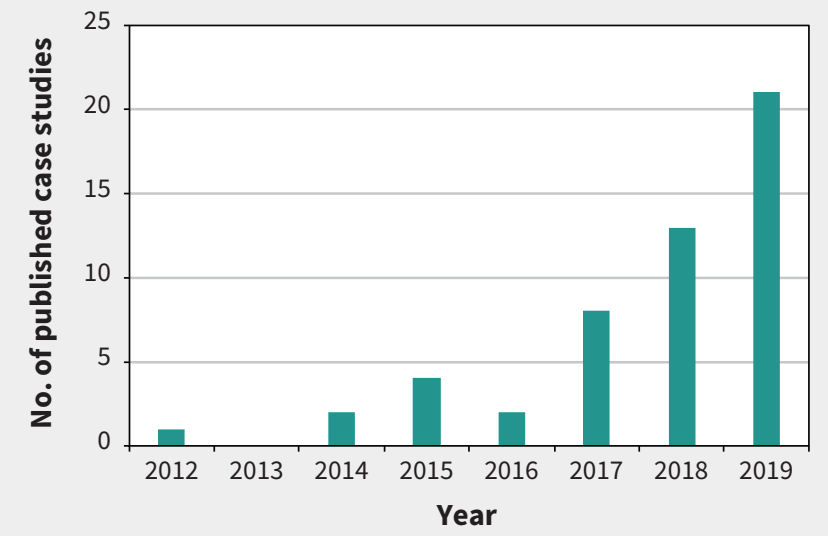

Figure 6: Number of published case reports and case series on vapingassociated pulmonary disease, by year published.

obstruction, with variable radiographic changes including mosaic attenuation, ground-glass opacities, bronchiectasis and centrilobular nodules. The time to diagnosis in these cases has often been delayed by many months after onset of symptoms, likely contributing to the variability in presentation. ${ }^{62-65}$ Our patient showed persistent airflow obstruction not reversible with bronchodilators and gas trapping on pulmonary function tests. Although CT did not show the classic mosaic attenuation indicative of gas trapping, CT images were taken during inhalation, not exhalation. Furthermore, the initial centrilobular nodules and later early mild bronchiectasis we observed could be in keeping with early bronchiolitis obliterans, even in the absence of mosaic attenuation. Unfortunately, our transbronchial biopsies did not contain airways, and surgical lung biopsy was deemed unsafe; therefore, we cannot confirm pathologically that this was bronchiolitis obliterans. Additionally, the exact causative agent(s) and mechanism of bronchial epithelial injury are unknown, though we speculate that vaping probably played a role given that no other possible cause was identified.

Following our reporting of this case to the Government of Canada as a vaping-related adverse event under the Canada Consumer Product Safety Act on Aug. 20, 2019, the CDC released its official health advisory statement on Aug. 30, 2019, regarding the multistate outbreak of severe pulmonary disease associated with use of e-cigarette products, most commonly, though not always, including use of THC (https://emergency. cdc.gov/han/han00421.asp). This report led us to re-examine our case and issue a follow-up report to Health Canada on Sept. 3, 2019. Similar to most cases reported to the CDC, our case involved a youth who vaped daily, used a variety of flavoured cartridges and reported use of THC products. Also similar to the most severe cases reported in the US, our patient required critical care and invasive mechanical ventilation, and his condition improved with administration of high-dose systemic corticosteroids. However, unlike in other cases, our patient had predominantly hypercapnic respiratory failure with severe obstructive physiology as the primary indication for ECMO, rather than diffuse alveolar damage and acute 
respiratory distress syndrome. In keeping with this, CT showed a diffuse tree-in-bud pattern rather than the bilateral groundglass opacities that characterize the surveillance case definition for the CDC investigation and Health Canada's national outbreak case definition. ${ }^{24}$

To date, "tree in bud" is an uncommon pattern in vapingrelated pulmonary disease. The current literature suggests that the most common imaging pattern is basilar-predominant consolidation and ground-glass opacity, often with areas of lobular or subpleural sparing, ${ }^{51}$ although previous case reports have described diverse imaging findings. ${ }^{5,9-11,19,20,34,39,42,51}$ Similarly, the pathologic findings can vary, ${ }^{13,26}$ although in the recent case series by Butt and colleagues, ${ }^{26}$ all cases showed 1 or more pattern or feature of acute lung injury, including acute fibrinous pneumonitis, diffuse alveolar damage, organizing pneumonia, interstitial edema, intra-alveolar fibrin and reactive type 2 pneumocyte hyperplasia. Additionally, airwaycentred accumulation of foamy macrophages in peribronchiolar airspaces was universally present, along with vacuolization of the cytoplasm of hyperplastic type 2 pneumocytes. In our case, foamy macrophages were rare; although there was mild interstitial septal thickening and type 2 pneumocyte hyperplasia, pneumocyte vacuolization was not reported.

Our case, the EVALI cases reported in the US and Canada, and the cases of serious adverse reactions to vaping reported in the medical literature to date depict a variety of pathophysiological presentations and severity of disease. This heterogeneity may be from exposure to different causative agents within the e-cigarettes; the combination of agents reacting in vitro or in vivo to generate new compounds with increased toxicity; ${ }^{66}$ the dose, solubility or temperature of the inhaled agent; or inhalational techniques determining whether the

Box 1: Some potential causes of pulmonary injury from vaping $52,53,66,68$

\begin{tabular}{ll} 
E-liquid component & \multicolumn{1}{c}{ Chemical or compound } \\
Carrier solution & - Propylene glycol \\
- Vegetable glycerin & - Diacetyl \\
- $2,3-$ Pentanedione & - Acetoin \\
& - Nicotine \\
- Tetrahydrocannabinol & - Cannabidiol \\
Additives & Butane hash oil \\
& - Other oil-rich additives \\
& - Vitamin E acetate (tetrahydrocannabinol \\
& adulterant) \\
Adulterants & - Carbonyls from heating propylene \\
& glycol and vegetable glycerin \\
Aerosol emissions & Particulates \\
& - Trace metal elements \\
& Volatile organic compounds \\
& - Bacterial endotoxins \\
- Fungal glucans
\end{tabular}

compound is deposited in the airways or alveoli. Although the exact causative agent(s) and mechanisms of respiratory injury are unknown at this time, there is growing evidence that several compounds present in e-liquids may pose risk of harm when inhaled.

E-cigarettes are known to contain harmful substances, including nicotine, vitamin E acetate, volatile organic compounds, heavy metals, ultra-fine particles and carbonyl compounds $3,23,52,53,66,67$ (Box 1). Of particular concern is the use of flavouring agents in e-liquids. There are more than 7700 e-liquid flavours across 460 brands. ${ }^{69}$ Although many of these flavours are "generally recognized as safe" under the US Federal Food, Drug, and Cosmetic Act, it is important to recognize that this applies only to ingestion; ${ }^{68}$ aerosolization of flavours safe for ingestion may produce adverse health effects that are yet undetermined..$^{70}$

A key example of a flavouring agent that is safe for ingestion but not inhalation is diacetyl (2,3-butanedione). Diacetyl belongs to a class of organic compounds referred to as diketones and is known for its characteristic butter flavour. ${ }^{71}$ It is found naturally in some foods and used as a synthetic flavouring agent in butter, cocoa, caramel, coffee, dairy products and alcoholic beverages. ${ }^{71}$ Occupational diacetyl inhalation is associated with decline in respiratory function, obstructive lung disease and decreased $\mathrm{FEV}_{1},{ }^{55}$ as well as bronchiolitis obliterans. ${ }^{57}$ Bronchiolitis obliterans from diacetyl exposure is also known as "popcorn worker's lung" owing to its initial description in patient clusters of microwave-popcorn factory workers exposed to diacetylbased flavouring agents. ${ }^{55-57}$ Diacetyl and another flavouring agent, 2,3-pentanedione, can alter gene expression pathways related to cilia and cytoskeletal processes in normal human bronchial epithelial cells, ${ }^{72}$ and cause epithelial cell injury and bronchiolitis obliterans in rodents. ${ }^{73,74}$ Although the mechanisms behind bronchiolitis obliterans remain incompletely understood, inhaled diacetyl influences human cellular matrix remodelling and may stimulate fibroproliferative changes in human airways. ${ }^{75}$

Diacetyl has been identified in e-liquids at levels higher than recommended safety limits, including in some products in which the packaging clearly stated that diacetyl was not an ingredient. ${ }^{76}$ One study found it in more than $60 \%$ of e-cigarette flavour samples analyzed, ${ }^{68}$ and another study showed that diacetyl is generated within e-liquids over time from another flavouring agent, acetoin. ${ }^{77}$ The chemical synthesis of diacetyl from acetoin is accelerated when nicotine is added to vaping fluid, with diacetyl concentrations increasing over time. ${ }^{77}$ Vaping fluid that is stored for a prolonged period could therefore accumulate high levels of diacetyl that, when vapourized, may increase risk for pulmonary toxicity. Our patient's vaping liquid was not available for analysis, but similarly flavoured products have been shown to contain flavouring agents including diacetyl. ${ }^{68}$

Our patient also vaped THC, which has been identified as an exposure in most recent cases: among 86 patients in Illinois and Wisconsin, $87 \%$ reported vaping THC products. ${ }^{54}$ In the 
preliminary report published by Layden and colleagues, 41 patients completed extensive interviews. ${ }^{22} \mathrm{~A}$ total of $80 \%$ reported using THC products, $61 \%$ reported using nicotine products and $7 \%$ reported using cannabidiol products; $44 \%$ reported using both nicotine and THC products, while $37 \%$ reported using only $\mathrm{THC}$ products and $17 \%$ used only nicotinecontaining products. ${ }^{22}$ Patients reported using numerous brands in a wide range of flavours, though details on the exact flavouring agents used were not provided. The investigation involves a wide variety of substances and e-cigarette products. Although the CDC has identified vitamin E acetate as a chemical of concern in their investigation, evidence is not yet sufficient to rule out other chemicals still under investigation; there may be more than one cause, and it is not yet known whether other agents play a role in the outbreak. ${ }^{23}$ Likewise, we cannot pinpoint the causative agent(s) responsible for our patient's pulmonary illness, as he vaped a variety of substances of which more than one may be a causative agent for harm.

E-cigarettes were first marketed in North America as a safer alternative to smoking traditional tobacco cigarettes and as a potential smoking-cessation aid. However, with heavy marketing, an enticing array of flavours and the potential to inhale drugs other than nicotine, vaping has become increasingly popular, particularly among youth. Until recently, reporting and surveillance mechanisms for adverse health effects related to e-cigarette use in Canada were limited. Following the CDC health advisory statement on Aug. 30, 2019 (https://emergency.cdc.gov/han/han00421.asp), Health Canada issued a warning on Sept. 4, 2019, regarding the potential risk of pulmonary illness associated with vaping. ${ }^{49}$ Simultaneously, the Public Health Agency of Canada alerted provincial and territorial public health officials to report possible cases in their jurisdictions. ${ }^{25}$

As of Nov. 12, 2019, there have been 2 confirmed cases of vaping-associated pulmonary illness in Quebec, 2 probable cases in New Brunswick and 3 probable cases in British Columbia. ${ }^{25}$ In addition to highlighting the need for improved surveillance, the Canadian Heart and Stroke Foundation is suggesting that the federal and provincial governments dedicate research funding to understanding the patterns of use and potential benefits of e-cigarettes as a smoking-cessation tool as well as their possible risks. ${ }^{78}$ The sale of nicotine-containing e-cigarette products to adults became legal in Canada in May 2018 through the Tobacco and Vaping Products Act. The recent outbreak of cases and deaths related to vaping has led the US government to propose moving to ban all flavoured e-cigarettes other than tobacco-flavoured products in the coming months, ${ }^{79}$ and Thailand, India and Brazil have moved to ban e-cigarettes completely. The Canadian Heart and Stroke Foundation is calling for a ban on the sale of e-liquid flavours that are attractive to youth, regulations to minimize the toxic additives in e-liquids, and raising the minimum age of purchase for both tobacco and e-cigarettes to 21 years of age. ${ }^{78}$ At this time, there are no proposed changes to the Tobacco and Vaping Products Act in Canada.

\section{Limitations}

The patient, his family and his health care team recognized the need to raise public awareness around this index case of vaping-related illness in Canada; however, this work has several limitations. The transbronchial biopsies did not include airway mucosa for evaluation, and because of the preparation method, no staining for lipoid pneumonia could be done. The bronchoscopies and biopsies were performed after initiation of antibiotics. Although the patient's severe hypercapnia predated the iatrogenic pneumothorax, the difficulty ventilating the patient may have been exacerbated by the pneumothorax. Finally, although a careful history of the products vaped was obtained, no vaping products were available for analysis. Regarding our literature review, we searched MEDLINE and Embase databases without restriction of language; however, we did not search biomedical databases originating in China, the country of origin for e-cigarettes.

\section{Conclusion}

This case of acute, life-threatening bronchiolitis resulting in fixed, chronic airflow obstruction in a previously healthy youth highlights the need for further research on the epidemiology of e-cigarette use, its addictive potential, and the short- and long-term risks and mechanisms of injury associated with vaping. Furthermore, there is urgent need for tighter regulation of the vaping industry, including marketing, ingredient disclosure, sale to youth, and testing of e-liquid components that may be "generally regarded as safe" for ingestion but may pose risk of serious harm when inhaled.

\section{References}

1. Canadian Tobacco, Alcohol and Drugs Survey (CTADS): summary of results for 2017. Ottawa: Health Canada; modified 2019 Jan. 4. Available: www.canada. ca/en/health-canada/services/canadian-tobacco-alcohol-drugs-survey/2017 -summary.html (accessed 2019 Nov. 17).

2. Czoli CD, Hammond D, White CM. Electronic cigarettes in Canada: prevalence of use and perceptions among youth and young adults. Can J Public Health 2014;105:e97-102.

3. E-cigarette use among youth and young adults. a report of the Surgeon General. Rockville (MD): US Department of Health Human Services; 2016.

4. Hammond D, Reid JL, Rynard VL, et al. Prevalence of vaping and smoking among adolescents in Canada, England, and the United States: repeat national cross sectional surveys. BMJ 2019;365:12219.

5. Attis M, King J, Hardison D, et al. The journey to ECMO could start with a single vape: a case of severe hypersensitivity pneumonitis in a pediatric patient [lecture]. Proceedings of the 29th Annual Extracorporeal Life Support Organization Conference; 2018 Sept. 13-16; Scottsdale (AZ). 2018:14.

6. Zaborniak K, Kalicinsky C. Hypersensitivity pneumonitis in the setting of electronic cigarette use: a case report [abstract]. Proceedings of the Canadian Society of Allergy and Clinical Immunology Annual Scientific Meeting 2018. Allergy Asthma Clin Immunol 2019;15:A81.

7. Narang R, Narang D, Narang S, et al. Good, bad, and ugly on vaping. Chest 2015;148(Suppl):385A. doi: 10.1378/chest.2279115.

8. Sommerfeld CG, Weiner DJ, Nowalk A, et al. Hypersensitivity pneumonitis and acute respiratory distress syndrome from e-cigarette use. Pediatrics 2018;141:e20163927.

9. Agustin M, Yamamoto M, Cabrera F, et al. Diffuse alveolar hemorrhage induced by vaping. Case Rep Pulmonol 2018;2018:9724530.

10. Baumann B. A case of organizing pneumonia secondary to use of an electronic nicotine delivery system [abstract]. Canadian Journal of Respiratory, Critical Care, and Sleep Medicine 2019;3(Suppl 1):9.

11. Khan MS, Khateeb FM, Khan Z, et al. A case of organizing pneumonia related to electronic cigarette use [abstract]. Am J Respir Crit Care Med 2018;197:A3566. 
12. He T, Oks M, Esposito M, et al. "Tree-in-bloom": severe acute lung injury induced by vaping cannabis oil. Ann Am Thorac Soc 2017;14:468-70.

13. Mukhopadhyay $S$, Mehrad M, Dammert $P$, et al. Lung biopsy findings in severe pulmonary illness associated with e-cigarette use (vaping). Am J Clin Pathol 2019 Oct. 17 [Epub ahead of print]. doi: 10.1093/ajcp/aqz182.

14. Boland JM, Aesif SW. Vaping-associated lung injury: nonspecific histopathologic findings necessitate a clinical diagnosis. Am J Clin Pathol 2019 Oct. 25 [Epub ahead of print]. doi: 10.1093/ajcp/aqz191.

15. Arter ZL, Wiggins A, Hudspath C, et al. Acute eosinophilic pneumonia following electronic cigarette use. Respir Med Case Rep 2019;27:100825.

16. Thota D, Latham E. Case report of electronic cigarettes possibly associated with eosinophilic pneumonitis in a previously healthy active-duty sailor. $J$ Emerg Med 2014;47:15-7.

17. McCauley L, Markin C, Hosmer D. An unexpected consequence of electronic cigarette use. Chest 2012;141:1110-3.

18. Viswam D, Trotter S, Burge PS, et al. Respiratory failure caused by lipoid pneumonia from vaping e-cigarettes. BMJ Case Rep 2018;2018. pii: bcr-2018-224350.

19. Holdorf J, Carpenter D, Kopec S. Is it the E.N.D.S.? Chest 2016;150(Suppl):502A. doi: 10.1016/j.chest.2016.08.516.

20. Modi S, Sangani R, Alhajhusain A. Acute lipoid pneumonia secondary to e-cigarettes use: an unlikely replacement for cigarettes. Chest 2015; 148(Suppl):382A. doi: 10.1378/chest.2274860.

21. Maddock SD, Cirulis MM, Callahan SJ, et al. Pulmonary lipid-laden macrophages and vaping. N Engl J Med 2019;381:1488-9.

22. Layden JE, Ghinai I, Pray I, et al. Pulmonary illness related to e-cigarette use in Illinois and Wisconsin - preliminary report. N Engl J Med 2019 Sept. 6 [Epub ahead of print]. doi: 10.1056/NEJMoa1911614.

23. Outbreak of lung injury associated with the use of e-cigarette, or vaping, products. Atlanta: Centers for Disease Control and Prevention; updated 2019 Nov. 14. Available: www.cdc.gov/tobacco/basic_information/e-cigarettes/severe -lung-disease.html (accessed 2019 Nov. 14).

24. National outbreak case definitions: severe pulmonary disease associated with vaping or dabbing. Ottawa: Public Health Agency of Canada; revised 2019 Sept. 25. Available: www.canada.ca/en/public-health/services/diseases/ vaping-pulmonary-illness/health-professionals/national-case-definition.html (accessed 2019 Nov. 7)

25. Severe lung illness related to vaping. Ottawa: Public Health Agency of Canada; modified 2019 Nov. 14. Available: www.canada.ca/en/public-health/services/ diseases/vaping-pulmonary-illness.html (accessed 2019 Nov. 14).

26. Butt YM, Smith ML, Tazelaar HD, et al. Pathology of vaping-associated lung injury. N Engl J Med 2019;381:1780-1.

27. Itoh M, Aoshiba K, Herai $\mathrm{Y}$, et al. Lung injury associated with electronic cigarettes inhalation diagnosed by transbronchial lung biopsy. Respirol Case Rep 2017;6:e00282.

28. Bakre SA, Al-Farra TS, Al-Farra S. Diffuse alveolar damage and e-cigarettes: case report and review of literature. Respir Med Case Rep 2019;28:100935.

29. Marasco RD, Loizzi D, Ardò NP, et al. Spontaneous pneumomediastinum after electronic cigarette use. Ann Thorac Surg 2018;105:e269-71.

30. Fastag E, DeBruin WJ. Spontaneous pneumomediastrinum in an adolescent: case report and literature review. 23rd Pediatric Critical Care Colloquium; 2016 Nov. 11-13. Pediatr Crit Care Med 2017;18;7:298-310

31. Lo T. Vaping and tension pneumothorax: a life-threatening association [abstract]. Am J Respir Crit Care Med 2017;195:A2052.

32. Skertich NJ, Sullivan GA, Madonna MB, et al. Vaping is a risk factor for spontaneous pneumothorax: two cases. J Pediatr Surg Case Rep 2019;50:101305. doi: 10.1016/j.epsc.2019.101305.

33. Bonilla A, Blair AJ, Alamro SM, et al. Recurrent spontaneous pneumothoraces and vaping in an 18-year-old man: a case report and review of the literature. $J$ Med Case Rep 2019;13:283.

34. Poponea N, Shehada E, Freeman N. The dark side of vaping; acute dyspnea and granulomatous lung disease associated with electronic cigarettes [abstract]. Am J Respir Crit Care Med 2018;197:A3565.

35. Lin C, Choi H. Granulomatosis due to electronic cigarette use [poster]. Chest 2019;156(Suppl):A2093.

36. Bradford LE, Rebuli ME, Ring BJ, et al. Danger in the vapor? ECMO for adolescents with status asthmaticus after vaping. J Asthma 2019 July 27 [Epub ahead of print]. doi: 10.1080/02770903.2019.1643361.

37. Hureaux J, Drouet M, Urban T. A case report of subacute bronchial toxicity induced by an electronic cigarette. Thorax 2014;69:596-7.

38. Sturek J, Malik N. Acute hypoxic respiratory failure with crazy paving associated with electronic cigarette use. Chest 2017;152(Suppl):A746. doi: 10.1016/j.chest.2017.08.776.

39. Carter T, Tucker D, Kilic A, et al. Life-threatening vesicular bronchial injury requiring veno-venous extracorporeal membrane oxygenation rescue in an electronic nicotine delivery system user. Clin Pract Cases Emerg Med 2017;1:212-7.
40. Atkins G, Drescher F. Acute inhalational lung injury related to the use of elec tronic nicotine delivery system (ENDS). Chest 2015;148(Suppl):83A.

41. Flower M, Nandakumar L, Singh M, et al. Respiratory bronchiolitis-associated interstitial lung disease secondary to electronic nicotine delivery system use confirmed with open lung biopsy. Respirol Case Rep 2017;5:e00230.

42. Helgeson A, Brooks J, Lobo F. A case of hypereosinophilia and eosinophilic asthma due to electronic cigarette use. In: Allergy and Asthma Proceedings. Providence (RI): Oceanside Publications Inc.; 2017.

43. Ring Madsen L, Vinther Krarup NH, Bergmann TK, et al. A cancer that went up in smoke: pulmonary reaction to e-cigarettes imitating metastatic cancer. Chest 2016;149:e65-7.

44. Bitetzakis CJ, Diaz Leyva J, Mazalewski W, et al. Pleural effusion with electronic cigarette use: a not-so-safe alternative to tobacco [abstract]. Hospital Medicine meeting; 2018 Apr. 8-11; Orlando (FL).

45. Macedonia TV, Krefft S, Rose CS, et al. Severe fixed obstructive lung disease in a former smoker with heavy e-cigarette use [abstract]. Am J Respir Crit Care Med 2018;197:A3572

46. Frossard SM, Volansky PM, Endara-Bravo AS. Acute uvulitis secondary to elec tronic cigarette use [abstract]. Am J Respir Crit Care Med 2015;191:A1556.

47. Perrine CG, Pickens CM, Boehmer TK, et al.; Lung Injury Response Epidemiology/ Surveillance Group. Characteristics of a multistate outbreak of lung injury associated with e-cigarette use, or vaping - United States, 2019. MMWR Morb Mortal Wkly Rep 2019;68:860-4.

48. Canada Consumer Product Safety Act (S.C. 2010, c.21). Available: https://laws justice.gc.ca/eng/acts/C-1.68/index.html (accessed 2019 Nov. 7).

49. Information update [September 4, 2019] - Health Canada warns of potential risk of pulmonary illness associated with vaping products. Ottawa: Health Canada; modified 2019 Oct. 17. Available: https://healthycanadians.gc.ca/ recall-alert-rappel-avis/hc-sc/2019/70919a-eng.php (accessed 2019 Nov. 7).

50. Information update [September 28, 2019] - Health Canada warns of potential risk of pulmonary illness associated with vaping products. Ottawa: Health Canada; modified 2019 Oct. 17. Available: https://healthycanadians.gc.ca/ recall-alert-rappel-avis/hc-sc/2019/70919a-eng.php (accessed 2019 Nov. 7).

51. Henry TS, Kanne JP, Kligerman SJ. Imaging of vaping-associated lung disease. N Engl J Med 2019;381:1486-7.

52. Lewis N, McCaffrey K, Sage K, et al. E-cigarette use, or vaping, practices and characteristics among persons with associated lung injury - Utah, April-October 2019. MMWR Morb Mortal Wkly Rep 2019;68:953-6.

53. Triantafyllou GA, Tiberio PJ, Zou RH, et al. Vaping-associated acute lung injury: a case series. Am J Respir Crit Care Med 2019 Oct. 1 [Epub ahead of print]. doi: 10.1164/rccm.201909-1809LE.

54. Ghinai I, Pray IW, Navon L, et al. E-cigarette product use, or vaping, among persons with associated lung injury - Illinois and Wisconsin, April-September 2019. MMWR Morb Mortal Wkly Rep 2019;68:865-9.

55. Kreiss K, Gomaa A, Kullman G, et al. Clinical bronchiolitis obliterans in workers at a microwave-popcorn plant. N Engl J Med 2002;347:330-8.

56. Kanwal R, Kullman G, Piacitelli C, et al. Evaluation of flavorings-related lung disease risk at six microwave popcorn plants. J Occup Environ Med 2006; 48:149-57.

57. Schwarz MI, King TE. Interstitial lung disease, 5th edition. Shelton (CT): People's Medical Publishing House; 2011.

58. Eisenhuber E. The tree-in-bud sign. Radiology 2002;222:771-2.

59. Miller WT Jr, Panosian JS. Causes and imaging patterns of tree-in-bud opacities. Chest 2013;144:1883-92.

60. King TJ. Bronchiolitis. In: Interstitial Lung Disease. 2011:1003.

61. Kreiss K. Occupational causes of constrictive bronchiolitis. Curr Opin Allergy Clin Immunol 2013;13:167-72.

62. Kanwal R. Bronchiolitis obliterans in workers exposed to flavoring chemicals. Curr Opin Pulm Med 2008;14:141-6.

63. Centers for Disease Control and Prevention (CDC). Fixed obstructive lung disease in workers at a microwave popcorn factory - Missouri, 2000-2002. MMWR Morb Mortal Wkly Rep 2002;51:345.

64. Centers for Disease Control and Prevention (CDC). Fixed obstructive lung disease among workers in the flavor-manufacturing industry - California, 2004-2007. MMWR Morb Mortal Wkly Rep 2007;56:389-93.

65. Centers for Disease Control and Prevention (CDC). Obliterative bronchiolitis in workers in a coffee-processing facility - Texas, 2008-2012. MMWR Morb Mortal Wkly Rep 2013;62:305-7.

66. Christiani DC. Vaping-induced lung injury. N Engl J Med 2019 Sept. 6 [Epub ahead of print]. doi: 10.1056/NEJMe1912032.

67. National Academies of Sciences, Engineering, and Medicine; Health and Medicine Division; Board on Population Health and Public Health Practice; Committee on the Review of the Health Effects of Electronic Nicotine Delivery Systems. Public health consequences of e-cigarettes. Washington (DC): National Academies Press (US); 2018 
68. Klager S, Vallarino J, MacNaughton $\mathrm{P}$, et al. Flavoring chemicals and aldehydes in e-cigarette emissions. Environ Sci Technol 2017;51:10806-13.

69. Zhu S-H, Sun JY, Bonnevie E, et al. Four hundred and sixty brands of e-cigarettes and counting: implications for product regulation. Tob Control 2014;23(Suppl 3):iii3-9.

70. Safety assessment and regulatory authority to use flavors: focus on electronic nicotine delivery systems and flavored tobacco products. Washington (DC): Flavor and Extract Manufacturers Association of the United States; 2013, revised 2016 Sept. 26.

71. Mathews JM, Watson SL, Snyder RW, et al. Reaction of the butter flavorant diacetyl (2, 3-butanedione) with $\mathrm{N}$-a-acetylarginine: a model for epitope formation with pulmonary proteins in the etiology of obliterative bronchiolitis. $J$ Agric Food Chem 2010;58:12761-8.

72. Park H-R, O'Sullivan M, Vallarino J, et al. Transcriptomic response of primary human airway epithelial cells to flavoring chemicals in electronic cigarettes. Sci Rep 2019;9:1400.

73. Morgan DL, Jokinen MP, Price HC, et al. Bronchial and bronchiolar fibrosis in rats exposed to 2, 3-pentanedione vapors: implications for bronchiolitis obliterans in humans. Toxicol Pathol 2012;40:448-65.
74. Palmer SM, Flake GP, Kelly FL, et al. Severe airway epithelial injury, aberrant repair and bronchiolitis obliterans develops after diacetyl instillation in rats. PLoS One 2011;6:e17644.

75. Brass DM, Gwinn WM, Valente AM, et al. The diacetyl-exposed human airway epithelial secretome: new insights into flavoring-induced airways disease. Am J Respir Cell Mol Biol 2017;56:784-95.

76. Farsalinos KE, Kistler KA, Gillman G, et al. Evaluation of electronic cigarette liquids and aerosol for the presence of selected inhalation toxins. Nicotine Tob Res 2015;17:168-74.

77. Vas CA, Porter A, McAdam K. Acetoin is a precursor to diacetyl in e-cigarette liquids. Food Chem Toxicol 2019;133:110727.

78. E-cigarettes in Canada. Ottawa: Heart and Stroke Canada; 2018. Available: www.heartandstroke.ca/-/media/pdf-files/position-statements/ecigarettes incanada.ashx?la=en\&hash=8939FF52C37A5E11C551176982F2E4AC5D 38D605 (accessed 2019 Nov. 7).

79. Vazquez M, Klein B. Trump administration moves to ban flavoured e-cigarettes CNN 2019 Sept. 11. Available: www.cnn.com/2019/09/11/politics/donald -trump-vape-e-cigarette-flavors/index.html (accessed 2019 Nov. 7).

\section{Competing interests: None declared.}

This article has been peer reviewed.

Affiliations: Divisions of Respirology (Landman, Dhaliwal, Mackenzie, Bosma), Clinical Pharmacology and Toxicology (Mackenzie), and Critical Care Medicine (Bosma), Department of Medicine, Schulich School of Medicine \& Dentistry, Western University, London, Ont.; Ontario, Manitoba and Nunavut Poison Centres (Mackenzie), The Hospital for Sick Children; Division of Respirology (Martinu), Department of Medicine, Toronto Lung Transplant Program, University Health Network; Interdepartmental Division of Critical Care Medicine (Steel), Department of Anesthesiology, Faculty of Medicine, University of Toronto, Toronto, Ont.
Contributors: Simon Landman and Karen Bosma drafted the original version. Inderdeep Dhaliwal, Constance Mackenzie, Tereza Martinu and Andrew Steel provided interpretation of data for the work and critical revision for intellectual content. All authors provided feedback on revisions, provided final approval of the version to be published and agree to be accountable for all aspects of the work.

Data sharing: All of the extracted data from published case reports identified in the literature search are available in Appendix 2 (www.cmaj.ca/lookup/suppl/doi:10.1503/ cmaj.191402/-/DC1).

Acknowledgements: The authors thank Ms. Alla lansavitchene, professional medical librarian, for her assistance with the literature searches and retrieving full-text articles; Dr. Keith Kwan, pulmonary pathologist, for his review of this case and providing pathology slides and interpretation; and Dr. Ian Chan, chest radiologist, for reviewing and providing further interpretation of computed tomography images.

Accepted: Nov. 11, 2019

Correspondence to: Karen Bosma, KarenJ.Bosma@lhsc.on.ca 